\title{
KÜÇÜK GÜÇLÜ RÜZGAR TÜRBİNLERİ İÇİN FARKLI BİR BULANIK MANTIK KARAR VERİCİLI MGNİ METODU
}

\author{
Onur Özdal MENGí1 ${ }^{1}$ İsmail Hakkı ALTAŞ ${ }^{2}$ \\ ${ }^{1}$ Enerji Sistemleri Mühendisliği Bölümü, Giresun Üniversitesi, 28000 Giresun \\ ${ }^{2}$ Elektrik-Elektronik Mühendisliği Bölümü, Karadeniz Teknik Üniversitesi, 61080 Trabzon, \\ onurmengi@yahoo.com, ihaltas@ktu.edu.tr
}

(Geliş/Received: 10.05.2014; Kabul/Accepted: 16.10.2014)

\section{ÖZET}

$\mathrm{Bu}$ çalışmada rüzgar türbinlerinden maksimum verimin elde edilebilmesi için kullanılan farklı bir Maksimum Güç Noktası İzleyici (MGNI) tekniği anlatılmaktadır. Deneysel olarak kurulan ve testleri yapılan sistem; biri motor diğeri generatör olarak çalışan birbirine akuple edilmiş asenkron makinalardan oluşan rüzgar türbin emülatörü, transformatör, yüksek akımlı doğrultma devresi, kıyıcı, evirici, veri aktarım kartı ve bilgisayar ünitesi, akım ve gerilim algılayıcıları, yükler ve MATLAB/Simulink ortamında tasarlanan bulanık mantık tabanlı bir MGNİ yazılımdan oluşmaktadır. Sistemde rüzgardan elde edilebilecek tepe güç değeri bilgisayar tarafindan sürekli olarak hesaplanarak o anki ortam koşullarında beslenebilecek maksimum yük miktarı tespit edilebilmektedir. Bu sistem; ortamdan rüzgar hızı, basınç, sıcaklık, nem, v. b. bilgileri kullanmadan sadece sisteme ait akım ve gerilim bilgileri ile tepe güç noktası izleme yapması ve tasarlanan Bulanık Mantık Sonuçlandırıcı (BMS) bu akım ve gerilim bilgilerini kullanarak tepe güç değerini sürekli olarak hesaplayabilmesi bakımından yapılan diğer çalışmalardan ayrılmaktadır.

Anahtar Kelimeler: Maksimum güç noktası izleyici, rüzgar türbini, bulanık mantık sonuçlandırıcı, yenilenebilir enerji

\section{A DIFFERENT FUZZY DECISION MAKING MPPT METHOD FOR A MICRO POWER WIND TURBINE}

\begin{abstract}
In this study, a different Maximum Power Point Tracking (MPPT) technique to obtain maximum efficiency from wind turbines is mentioned. The system, which is experimentally established and tested, consists of a wind turbine emulator, which consists of asynchronous machines coupled to each other and one of them acts as the motor while the other is the generator, transformer, rectifier with high current, chopper, invertor, data acquisition card and computer unit, current and voltage sensors, loads and a fuzzy logic based MPPT software designed in MATLAB/Simulink environment. Maximum load to be fed in the case of existing environmental conditions can be defined by continuously calculating the maximum power value to be obtained from the wind by the computer. This system differs from the other studies in that it tracks maximum power point with only the current and voltage date of the system without taking wind power, pressure, heat, humidity etc into consideration; besides, the designed Fuzzy Logic Reasoning (FLR) can continuously calculate maximum power point by using this current and voltage data.
\end{abstract}

Keywords: Maximum power point tracking, wind turbine, fuzzy logic decision making, renewable energy

\section{GİRIŞ (INTRODUCTION)}

Rüzgar türbinleri enerji üretme amacı ile kullanılan yenilenebilir enerji kaynaklarından bir tanesidir. Rüzgardan aldığı hareket enerjisi ile dönen kanatların bağlı bulunduğu elektrik makinasının jeneratör olarak çalışması ile enerji üretimini gerçekleştirmektedir.
Pek çok ülke hem karbon salınımını hem de dışa bağımlılığını azaltmak için ihtiyaç duyduğu enerjinin bir kısmını rüzgardan sağlama yoluna gitmektedir. [1,2]. Araştırma amaçlı ülkemizde pek çok üniversitede ve enstitüde kurulan rüzgar türbinleri ile bu konuda araştırmalar hızla devam etmektedir. Hem kurulan gerçek rüzgar türbinleri olduğu gibi [3], 


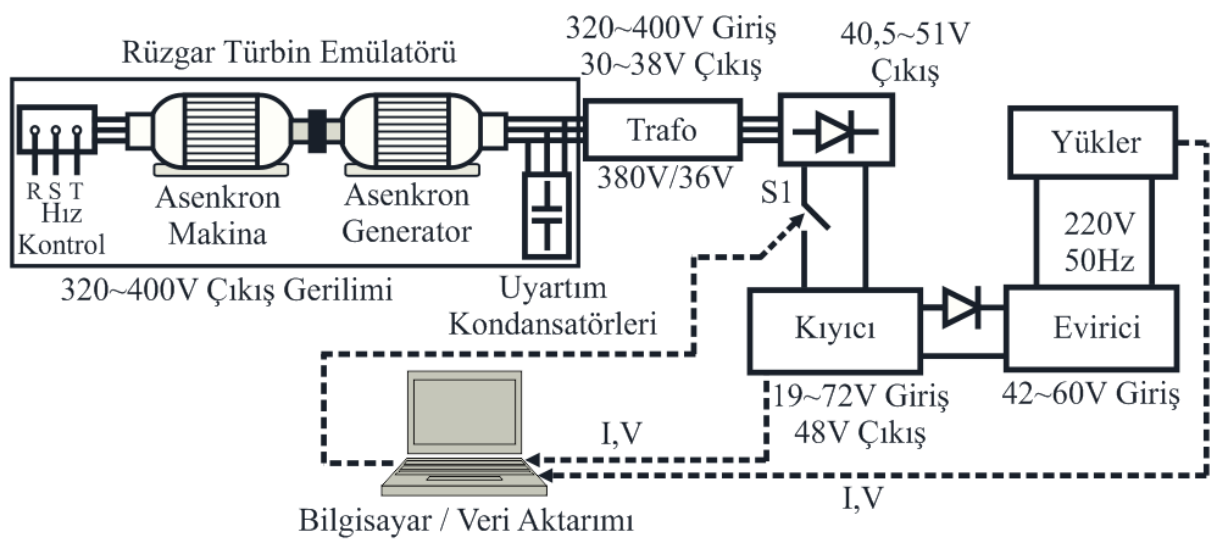

Şekil 1. Kurulan deneysel sistem (Experimental system)

laboratuvar ortamında birbirine akuple edilen değişik elektrik motorlarının kullanıldığı emülatörler de bulunmaktadır. Böylece gerçek türbin kurmadan çalışmalar yapılabilmektedir [4]. Piyasada 200300W'dan 8MW seviyelerine kadar güç üretebilen rüzgar türbinleri bulunmaktadır. Üzerinde deneme çalıșmaları yapılan ve $10-15 \mathrm{MW}$ seviyesinde güç üretebilen türbinlerde kısa süre sonra piyasada yerini alacaktır [5]. Rüzgar türbinlerinin verimli çalışabilmesi ve elde edilebilecek enerji seviyesinin maksimum olabilmesi için kullanılan MGNI' ler sistemin en önemli bileşenlerinden bir tanesi olmaktadır. Sistem, o anki rüzgar durumuna göre gerekli ölçümleri yaparak türbinin verebileceği maksimum gücü ayarlamaya çalışmaktadır. Maksimum verim için bu noktanın tespiti önemlidir [6]. Literatürde maksimum güç noktasını bulunması ve sistemin daha verimli çalıșması için; ortamdan rüzgar hızı ölçülerek elde edilen türbin rüzgar güç eğrilerini kullanarak tepe güç noktasının tespiti ve sistemin bu noktada tutulmaya çalışılması $[7,8]$ ve rüzgar güç üretim sistemlerinde kullanılan doğrultucu, evirici ve kıyıcı gibi güç elektroniği çeviricilerinin değişik metotlarla kontrolü $[9,10]$ gibi teknikler kullanılmaktadır. Ayrıca bulanık mantık [11,12], parçacık sürü optimizasyonu ve yapaya sinir ağları $[13,14]$ gibi pek çok ileri kontrol tekniğinin de rüzgar türbinlerinde, özellikle güç elektroniği çeviricilerini kontrol etmek için kullanıldıklarını görmekteyiz. Şekil 1'de deneysel olarak kurulan sistemin yapısı görülmektedir. Deneysel sistem rüzgar türbin emülatörü, trafo, köprü doğrultucu, kıyıcı, evirici, yükler, veri aktarım kartı ve bilgisayardan oluşmaktadır. Kurulan sistem ortamdan bir ölçüm almadan (rüzgar hızı, nem, basınç, sıcaklık v. s.) ya da güç elektroniği dönüştürücülerini kontrol etmeden kullandığı BMS ile rüzgar türbini emülatörünün verebileceği maksimum güç değerini hesaplayarak yükleri beslemesi bakımından diğer çalışmalardan ayrılmaktadır. Yani rüzgar türbinlerinde MGNI yapmaktadır. Böylece bilgisayar yük durumuna ve sistemden elde edilebilecek tepe güç değerine bakarak hangi yüklerin devreye alınacağını ya da çıkartılacağını ya da gücün yetmediği durumda yardımcı enerji üretim sistemlerini devreye almaya veya çıkarmaya karar verebilecektir. Sistemde sadece kıyıcıda ve yük tarafında 2 akım ve 2 gerilim, toplam 4 elektriksek büyüklüğü ölçerek bu kararları alabilmektedir.

Aktarılan veriler MATLAB/Simulink ortamında yazılan program aracılığı ile alınmakta ve sistemi bu akıllı program kontrol etmektedir.

\section{DENEY DÜZENEĞİ (EXPERIMENT SETUP)}

\subsection{Rüzgar Türbin Emülatörü (Wind Turbine Emulator)}

Rüzgar türbin emülatörü Şekil 2'de görülmektedir. Sistem iki adet birbirine akuple edilmiş asenkron makinadan oluşmaktadır. İki makina birbirine bir kayış vasıtası ile bağlanmıștır. Birinci makina, motor olarak ikincisi ise generatör olarak çalışmaktadır. Asenkron motor $5 \mathrm{~kW}$ ve asenkron generatör ise $3.5 \mathrm{~kW}$ 'lık bir güç değerine sahiptir. Her ikisi de sincap kafeslidir. Rüzgar hızındaki değişimleri modellemek ve makinalara yansıtabilmek için birinci motora bağlı bir sürücü bulunmaktadır. Sürücü hızı el ile ayarlanarak motor hızı değiștirilmektedir. Bu durumda sistemin üreteceği güç değeri sürekli olarak değiştirilmeye çalıșılmıştır. Sistem şebekeden bağımsız çalıştığı için asenkron generatörün ihtiyaç duyacağı reaktif güç, kondansatör grubundan temin edilmektedir.

Rüzgar Türbin Emülatörü

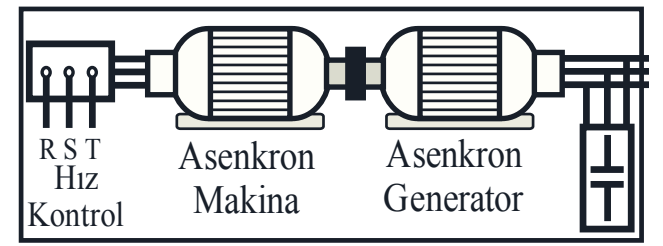

Şekil 2. Rüzgar türbin emülatörünün yapısı (Wind turbine emulator)

Kullanılan asenkron generatör: 3 fazlı, 4 kutuplu, $3.5 \mathrm{~kW}$ gücünde, $50 \mathrm{~Hz}$ frekansl1, $\operatorname{Cos} \varphi=0.80$ ve $1415 \mathrm{~d} /$ dak'lık bir motordur. Motor parametrelerinden 
yola çıkarak ihtiyaç duyulacak reaktif güç ve kondansatör değeri:

$\mathrm{P}=\mathrm{S} \cdot \operatorname{Cos} \varphi$

$3500=\mathrm{S} .0,8 \rightarrow \mathrm{S}=4375 \mathrm{VA}$

$\operatorname{Cos} \varphi=0,8$ ise $\varphi=36,86$ ve $\operatorname{Sin} \varphi=0,6$

$\mathrm{Q}=\mathrm{S} . \operatorname{Sin} \varphi$

$\mathrm{Q}=4375.0,6 \rightarrow \mathrm{Q}=2625 \mathrm{Var}$

Tek faz reaktif güç= $Q / 3=875 \mathrm{Var}$

$\mathrm{Q}=\mathrm{E} . \mathrm{I}_{\mathrm{C}}$

$\mathrm{I}_{\mathrm{C}}=\frac{\mathrm{Q}}{\mathrm{E}}=\frac{875}{380}=2,3 \mathrm{~A}$

$\mathrm{E}=\mathrm{X}_{\mathrm{C}} \cdot \mathrm{I}_{\mathrm{C}}$

$\mathrm{X}_{\mathrm{C}}=\frac{\mathrm{E}}{\mathrm{I}_{\mathrm{C}}}=\frac{380}{2,3}=165,2 \Omega$

$\mathrm{C}=\frac{1}{2 \cdot \pi \cdot f \cdot \mathrm{X}_{\mathrm{C}}}$

$\mathrm{C}=\frac{1}{2 . \pi \cdot 50 \cdot 165,2}=19,27 \mu \mathrm{F}$

şeklinde hesaplanır [15]. Burada aktif güç $(\mathrm{P})$, reaktif güç $(\mathrm{Q})$, görünür güç $(S)$, faz açısı $(\varphi)$, kondansatör gerilimi (E), Kondansatör akımı (IC), kondansatörün reaktansı $\left(\mathrm{X}_{\mathrm{C}}\right)$, frekans (f), kondansatör $(\mathrm{C})$ ile gösterilmektedir. Hesaplanan $19,27 \mu \mathrm{F}$ değerine en yakın değer $22 \mu \mathrm{F}$ denenmiş, fakat farklı hız değerlerinde sorun çıktığı için bu değer arttırılmış ve $33 \mu \mathrm{F}$ değerinde sistem geniş bir hız aralığında sorunsuz bir şekilde çalışmıştır.

\subsection{Diğer Sistem Bileşenleri (Another System Components)}

Emülatör çıkışında elde edilen $320 \mathrm{~V}$ ile $400 \mathrm{~V}$ arasındaki gerilim trafodan geçirilerek $30 \mathrm{~V}$ ile $38 \mathrm{~V}$ arasında bir değere indirilmektedir. $\mathrm{Bu}$ değerler rüzgar hızını modelleyen sürücü hızı değiştiği için sürekli olarak değişmektedir. Sürücü, V/f kontrolü yapan bir cihazdır ve frekans değiştirilerek motor hız ayarını yapmaktadır. Girişteki 320V ile 400V arasındaki değişim sürücüde $32 \mathrm{~Hz}$ ile $44 \mathrm{~Hz}$ arasına gelmektedir. Trafo $10.5(380 \mathrm{~V} / 36 \mathrm{~V})$ çevirme oranına sahiptir. Trafo 2.2kW'llk güce sahiptir. Trafo çıkışında elde edilen alternatif gerilim 3 fazlı 6 diyotlu doğrultucu kullanılarak doğru akıma çevrilmektedir. Rüzgar hızındaki değişim nedeniyle doğrultucu giriş ve çıkış değerleri de sürekli olarak değişmektedir. Doğrultucu girişi $30 \mathrm{~V}$ ile $38 \mathrm{~V}$ arasında değişmektedir. Çıkış gerilimi ise aşağıdaki gibi hesaplanır:

$\mathrm{V}_{\text {çıkıs }}=1.654 \mathrm{U}_{\mathrm{R}_{\mathrm{TEPE}}}$

Burada 3 faz köprü çıkış gerilimi $\left(\mathrm{V}_{\text {çııı̧ }}\right)$, tek faz tepe gerilim değeri ise $U_{R_{T E P E}}$ ile gösterilmektedir. Doğrultucu giriş gerilimi $30 \mathrm{~V}$ ile $38 \mathrm{~V}$ arasında değiştiği için çıkış gerilimi de $40.5 \mathrm{~V}$ ile $51 \mathrm{~V}$ arasında değişmektedir.

Elde edilen bu gerilim kıyıcının giriş gerilimi olmaktadır. Kıyıcı $19 \mathrm{~V}$ ile $72 \mathrm{~V}$ aralığındaki giriş gerilimini 48V çıkış gerilimi olarak sabitlemektedir. Kurulan sistemde kıyıcı giriş gerilimi $40.5 \mathrm{~V}$ ile $51 \mathrm{~V}$ arasında değişmektedir. Kullanılan elemanların birbiri ile uyum içinde çalışabilmesi için gereken giriş ve çıkış gerilim ayarlamaları yapılmaktadır. $\mathrm{Bu}$ nedenle kullanılan trafo da $380 \mathrm{~V} / 36 \mathrm{~V}$ olacak şekilde özel olarak yaptırılmıștır. Kıyıcı 1kW'lık bir güce sahiptir. Birbirine paralel olarak bağlanarak gücü arttırılabilir. Sistem $1 \mathrm{~kW}$ 'lık yük için ayarlanmıştır. Fakat $3 \mathrm{~kW}$ değerine kadar geliştirilebilir yapıdadır.

Sistemde $42 \mathrm{~V}$ ile $60 \mathrm{~V}$ arasındaki doğru gerilimi $220 \mathrm{~V} / 50 \mathrm{~Hz}$ alternatif gerilime çeviren bir evirici bulunmaktadır. Kıyıcı bir koruma diyotu üzerinden eviriciye bağlıdır. Kıyıcı çıkış gerilimi 48V'da sabit olduğu için sistem bir sıkıntı olmadan çalışmaktadır. Kullanılan evirici 3kW'lık güce sahiptir.

Rüzgar türbin enerji üretim sisteminde yük üzerindeki akım ve gerilim ile kıyıcı giriş gerilimi ve çıkış akımını ölçen 4 adet algılayıcı bulunmaktadır. Yük üzerindeki algılayıcılar tüketilen gücü hesaplamak için ve kıyıcıdaki algılayıcılar ise rüzgar türbin emülatöründen elde edilebilecek maksimum güç miktarını hesaplamak için kullanılmaktadır. Elde edilen bilgiler bir veri aktarım kartı aracılığı ile bilgisayara aktarılmaktadır.

\subsection{Bulanık Sonuçlandırıcılı MGNI Yazılımının Tasarımı (Maximum Power Point Tracking Software with Fuzzy Decision Making)}

Bulanık mantık kavramı uzun zamandan beri bilinmektedir. Giriş değişkenlerinin derecelendirilmesi ve bulanıklaştırılması ve belirli kurallar eşliğinde çalışan sistem, duruma uygun bir değer üreterek çıkışa aktarmaktadır. Bu şekilde kontrol sistemleri için kontrol işareti üretilebilmekte ya da kararlar alınabilmektedir. [16]. Şekil 3'de BMS'nın içyapısı görülmektedir. Burada kesin girişler önce bulanıklaştırma birimine gelir ve kesin değerler bulanıklaşır. Daha sonra kuralların işlendiği kısma gelen giriş değerleri burada işlenir ve sonuçlandırılır. Son olarak elde edilen değerler durulaştırılarak kesin çıkışlar elde edilir. 


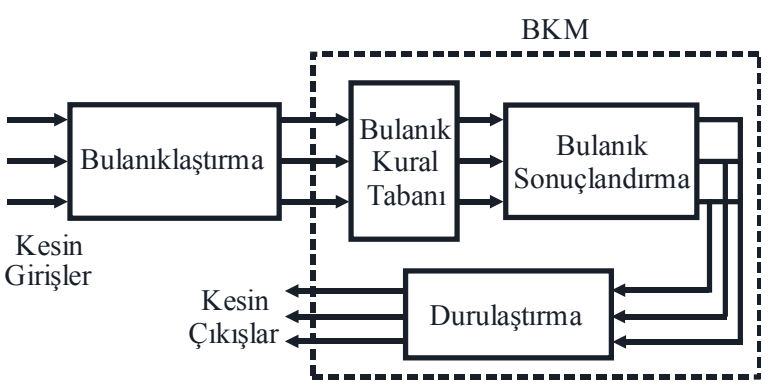

Şekil 3. BMS'nın yapısı (FDM's structure)

Rüzgar türbininde MGNİ için kıyıcı giriş gerilimi ( $\left.\mathrm{V}_{\mathrm{DC} / \mathrm{DC}_{\mathrm{G}}}\right)$ ve çıkış akım $\left(\mathrm{I}_{\mathrm{DC} / \mathrm{DC} C}\right)$ değerleri seçilmiş̧ir. Bunlar aynı zamanda BMS'nin giriş değişkenleridir. Kıyıcı çıkış gerilimi 48V'da sabittir. $\mathrm{Bu}$ değerlerin seçilmesindeki ana sebep kıyıcı giriş gerilimine bakarak dalgalanmaları tespit etmek ve kıyıcı çıkış akımına bakarak o anki güç değerini hesaplamaktır. $\mathrm{Bu}$ değer anlıktır ve çekilen güç hakkında bilgi verir.

Bu hesaplama;

$\mathrm{P}_{\mathrm{DC} / \mathrm{DC}}=48 \times \mathrm{I}_{\mathrm{DC} / \mathrm{DC} \mathrm{C}_{\zeta}}$

formülü ile yapılmaktadır. BMS'nin çıkış değeri ise o anki rüzgar hız durumuna göre elde edilebilecek tepe güç değeri bilgisidir. Burada üçgen üyelik fonksiyonları kullanılmıştır ve 7 kurallıdır.

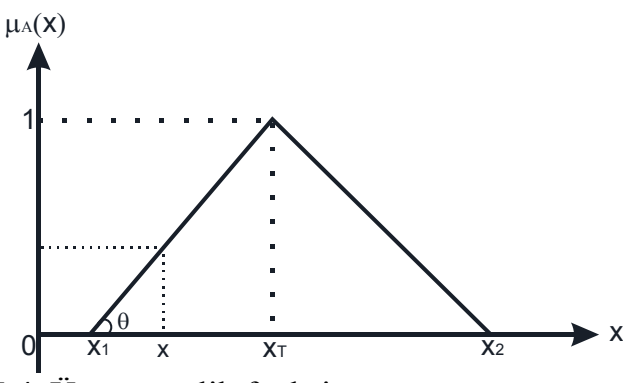

Şekil 4. Üçgen üyelik fonksiyonu (Triangular membership function)

Şekil 4'de üçgen üyelik fonksiyonu görülmektedir. Eşitlik 8'de üçgen üyelik fonksiyonlarına ait denklemler görülmektedir.

$$
\mu_{\mathrm{AU}}(\mathrm{x})=\max \left(\min \left(\frac{\mathrm{x}-\mathrm{x}_{1}}{\mathrm{x}_{\mathrm{T}}-\mathrm{x}_{1}}, \frac{\mathrm{x}_{2}-\mathrm{x}}{\mathrm{x}_{2}-\mathrm{x}_{\mathrm{T}}}\right), 0\right)
$$

Akım değeri 3.5A ile 23.5A değeri arasında değişmektedir. Üyelik fonksiyonları da bu değerlere göre $\mathrm{I}_{1}$ 'den $\mathrm{I}_{7}$ 'ye kadar değişmektedir.
Gerilim değerleri ise $27 \mathrm{~V}$ ile $48 \mathrm{~V}$ aralığında değişmekte ve üyelik fonksiyonları da $\mathrm{V}_{1}$ ile $\mathrm{V}_{7}$ arasında isim almaktadır. 27V'un altında güç üretilmemektedir. Son olarak çıkış güç değerleri (hesaplanan tepe güç değeri) $\mathrm{W}_{1}$ ile $\mathrm{W}_{7}$ arasında değişmektedir. Güç aralığı ise $100 \mathrm{~W}$ ile $1000 \mathrm{~W}$ arasında değişmektedir. BMS'nin sonuçlandırma bloğunda Eşitlik 9'da görülen ağırlık merkezi metodu kullanılmıştır [15].

$$
\mathrm{z}_{0}=\frac{\sum_{\mathrm{j}=1}^{\mathrm{n}} \mu_{\mathrm{C}}\left(\mathrm{z}_{\mathrm{j}}\right) \cdot \mathrm{z}_{\mathrm{j}}}{\sum_{\mathrm{j}=1}^{\mathrm{n}} \mu_{\mathrm{C}}\left(\mathrm{z}_{\mathrm{j}}\right)}
$$

Şekil 5'de BMS giriş ve çıkış değişkenleri görülmektedir.

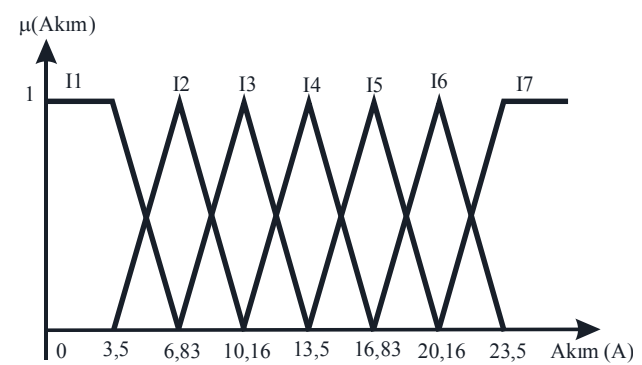

(a) $\mathrm{I}_{\mathrm{DC} / \mathrm{DC}_{\mathrm{C}}}$ üyelik fonksiyonları $\quad\left(\mathrm{I}_{\mathrm{DC} / \mathrm{DC} \mathrm{C}_{\mathrm{C}}}\right.$ membership functions)

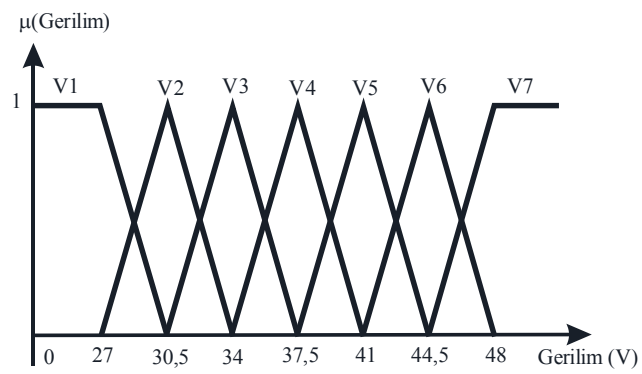

(b) $\mathrm{V}_{\mathrm{DC} / \mathrm{DC}}$ üyelik fonksiyonları $\left(\mathrm{V}_{\mathrm{DC} / \mathrm{DC} \mathrm{C}_{\mathrm{G}}}\right.$ membership functions)

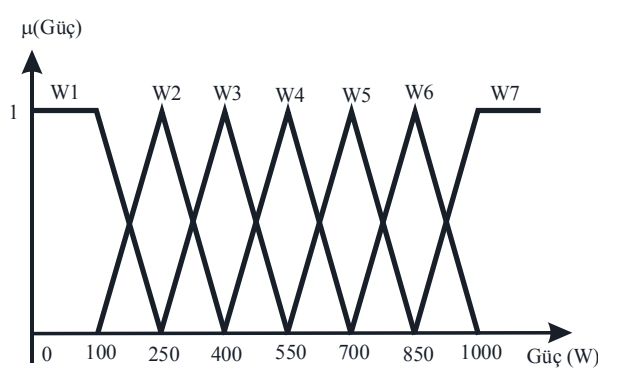

(c) Güç üyelik fonksiyonları (Power membership functions)

Şekil 5. BMS giriș ve çıkıș üyelik fonksiyonları (FDM input and output functions) 
Tablo 1. BMS kurallar (FDM rules)

\begin{tabular}{|c|c|c|c|c|}
\hline $\begin{array}{c}\text { Akım } \\
\text { (A) }\end{array}$ & $\begin{array}{c}\text { Gerilim } \\
\text { (V) }\end{array}$ & $\begin{array}{c}\text { Frekan } \\
\text { s } \\
(\mathrm{Hz}) \\
\end{array}$ & $\begin{array}{l}\text { Tepe } \\
\text { Güç } \\
(W)\end{array}$ & $\begin{array}{c}7 \text { Kural } \\
7 \text { Çıkış } \\
\text { FLR }\end{array}$ \\
\hline $\mathrm{I} 1 \rightarrow 3,5$ & $\mathrm{~V} 1 \rightarrow 27$ & 32,1 & 150 & W1 \\
\hline $\mathrm{I} 1 \rightarrow 3,5$ & $\mathrm{~V} 2 \rightarrow 30,5$ & 33,5 & 250 & W2 \\
\hline $\mathrm{I} 1 \rightarrow 3,5$ & $\mathrm{~V} 3 \rightarrow 34$ & 34,8 & 350 & W3 \\
\hline $\mathrm{I} 1 \rightarrow 3,5$ & $\mathrm{~V} 4 \rightarrow 37,5$ & 36,6 & 500 & W4 \\
\hline $\mathrm{I} 1 \rightarrow 3,5$ & $\mathrm{~V} 5 \rightarrow 41$ & 38,5 & 650 & W5 \\
\hline $\mathrm{I} 1 \rightarrow 3,5$ & $\mathrm{~V} 6 \rightarrow 44,5$ & 40,3 & 900 & W6 \\
\hline $\mathrm{I} 1 \rightarrow 3,5$ & $\mathrm{~V} 7 \rightarrow 48$ & 42,2 & 1000 & W7 \\
\hline $\mathrm{I} 2 \rightarrow 6,83$ & $\mathrm{~V} 1 \rightarrow 27$ & 33,6 & 250 & W2 \\
\hline $\mathrm{I} 2 \rightarrow 6,83$ & $\mathrm{~V} 2 \rightarrow 30,5$ & 34,6 & 350 & W3 \\
\hline $\mathrm{I} 2 \rightarrow 6,83$ & $\mathrm{~V} 3 \rightarrow 34$ & 36 & 450 & W3 \\
\hline $\mathrm{I} 2 \rightarrow 6,83$ & $\mathrm{~V} 4 \rightarrow 37,5$ & 37,6 & 550 & W4 \\
\hline $\mathrm{I} 2 \rightarrow 6,83$ & $\mathrm{~V} 5 \rightarrow 41$ & 39,4 & 750 & W5 \\
\hline $\mathrm{I} 2 \rightarrow 6,83$ & $\mathrm{~V} 6 \rightarrow 44,5$ & 41,2 & 925 & W7 \\
\hline $\mathrm{I} 2 \rightarrow 6,83$ & $\mathrm{~V} 7 \rightarrow 48$ & 43 & 1000 & W7 \\
\hline $\mathrm{I} 3 \rightarrow 10,16$ & $\mathrm{~V} 1 \rightarrow 27$ & 35,4 & 400 & W3 \\
\hline $\mathrm{I} 3 \rightarrow 10,16$ & $\mathrm{~V} 2 \rightarrow 30,5$ & 35,9 & 450 & W3 \\
\hline $\mathrm{I} 3 \rightarrow 10,16$ & $\mathrm{~V} 3 \rightarrow 34$ & 37,3 & 550 & W4 \\
\hline $\mathrm{I} 3 \rightarrow 10,16$ & $\mathrm{~V} 4 \rightarrow 37,5$ & 38,8 & 650 & W5 \\
\hline $\mathrm{I} 3 \rightarrow 10,16$ & $\mathrm{~V} 5 \rightarrow 41$ & 40,2 & 850 & W6 \\
\hline $\mathrm{I} 3 \rightarrow 10,16$ & $\mathrm{~V} 6 \rightarrow 44,5$ & 42 & 1000 & W7 \\
\hline $\mathrm{I} 3 \rightarrow 10,16$ & $\mathrm{~V} 7 \rightarrow 48$ & 43,8 & 1000 & W7 \\
\hline $\mathrm{I} 4 \rightarrow 13,5$ & $\mathrm{~V} 1 \rightarrow 27$ & - & - & W3 \\
\hline $\mathrm{I} 4 \rightarrow 13,5$ & $\mathrm{~V} 2 \rightarrow 30,5$ & 37,4 & 550 & W4 \\
\hline $\mathrm{I} 4 \rightarrow 13,5$ & $\mathrm{~V} 3 \rightarrow 34$ & 38,5 & 650 & W5 \\
\hline $\mathrm{I} 4 \rightarrow 13,5$ & $\mathrm{~V} 4 \rightarrow 37,5$ & 40 & 850 & W6 \\
\hline $\mathrm{I} 4 \rightarrow 13,5$ & $\mathrm{~V} 5 \rightarrow 41$ & 41,4 & 950 & W7 \\
\hline $\mathrm{I} 4 \rightarrow 13,5$ & $\mathrm{~V} 6 \rightarrow 44,5$ & - & 1000 & W7 \\
\hline $\mathrm{I} 4 \rightarrow 13,5$ & $\mathrm{~V} 7 \rightarrow 48$ & - & 1000 & W7 \\
\hline $\mathrm{I} 5 \rightarrow 16,83$ & $\mathrm{~V} 1 \rightarrow 27$ & - & - & W4 \\
\hline $\mathrm{I} 5 \rightarrow 16,83$ & $\mathrm{~V} 2 \rightarrow 30,5$ & 39,2 & 700 & W5 \\
\hline $\mathrm{I} 5 \rightarrow 16,83$ & $\mathrm{~V} 3 \rightarrow 34$ & 39,8 & 850 & W6 \\
\hline $\mathrm{I} 5 \rightarrow 16,83$ & $\mathrm{~V} 4 \rightarrow 37,5$ & 41 & 900 & W6 \\
\hline $\mathrm{I} 5 \rightarrow 16,83$ & $\mathrm{~V} 5 \rightarrow 41$ & - & 1000 & W7 \\
\hline $\mathrm{I} 5 \rightarrow 16,83$ & $\mathrm{~V} 6 \rightarrow 44,5$ & - & 1000 & W7 \\
\hline $\mathrm{I} 5 \rightarrow 16,83$ & $\mathrm{~V} 7 \rightarrow 48$ & - & 1000 & W7 \\
\hline $\mathrm{I} 6 \rightarrow 20,16$ & $\mathrm{~V} 1 \rightarrow 27$ & - & - & W5 \\
\hline $\mathrm{I} 6 \rightarrow 20,16$ & $\mathrm{~V} 2 \rightarrow 30,5$ & 40,2 & 850 & W6 \\
\hline I6 $\rightarrow 20,16$ & $\mathrm{~V} 3 \rightarrow 34$ & 41,3 & 950 & W7 \\
\hline I6 $\rightarrow 20,16$ & $\mathrm{~V} 4 \rightarrow 37,5$ & - & 1000 & W7 \\
\hline $\mathrm{I} 6 \rightarrow 20,16$ & $\mathrm{~V} 5 \rightarrow 41$ & - & 1000 & W7 \\
\hline $\mathrm{I} 6 \rightarrow 20,16$ & $\mathrm{~V} 6 \rightarrow 44,5$ & - & 1000 & W7 \\
\hline $\mathrm{I} 6 \rightarrow 20,16$ & $\mathrm{~V} 7 \rightarrow 48$ & - & 1000 & W7 \\
\hline $\mathrm{I} 7 \rightarrow 23,5$ & $\mathrm{~V} 1 \rightarrow 27$ & - & - & W6 \\
\hline $\mathrm{I} 7 \rightarrow 23,5$ & $\mathrm{~V} 2 \rightarrow 30,5$ & - & - & W6 \\
\hline $\mathrm{I} 7 \rightarrow 23,5$ & $\mathrm{~V} 3 \rightarrow 34$ & - & 1000 & W7 \\
\hline $\mathrm{I} 7 \rightarrow 23,5$ & $\mathrm{~V} 4 \rightarrow 37,5$ & - & 1000 & W7 \\
\hline $\mathrm{I} 7 \rightarrow 23,5$ & $\mathrm{~V} 5 \rightarrow 41$ & - & 1000 & W7 \\
\hline $\mathrm{I} 7 \rightarrow 23,5$ & $\mathrm{~V} 6 \rightarrow 44,5$ & - & 1000 & W7 \\
\hline $\mathrm{I} 7 \rightarrow 23,5$ & $\mathrm{~V} 7 \rightarrow 48$ & - & 1000 & W7 \\
\hline
\end{tabular}

Tablo 1'de BMS'da kullanılan kurallar görülmektedir. Buradaki değerler BMS için yapılan yüzlerce deneme neticesinde belirlenmiş kurallardır. Tablolarda sürücü frekans değeri değiştirilerek motor hızı/rüzgar hızı ayarlandığı için bu değerler de dahil edilmiştir. Sistem çökme noktasına gelene kadar zorlanmış ve besleyebildiği son güç değerleri kaydedilmiştir. Sistemde aşırı yük anında evirici devreden çıkarak kendini kapatmaktadır. Bu işlemlerin sonunda Tablo 2'de işlenen kurallar elde edilmiştir. Burada BMS kullanılmasının ana nedeni Tablo 3'te 4'den daha rahat
Tablo 2. BMS'da işlenen kurallar (Process rules in

\begin{tabular}{|c|c|c|c|c|c|c|c|c|}
\hline \multirow{2}{*}{\multicolumn{2}{|c|}{$\Delta \mathbf{P}$}} & \multicolumn{7}{|c|}{ AKIM } \\
\hline & & I1 & 12 & 13 & I4 & 15 & 16 & 17 \\
\hline \multirow{7}{*}{ GERILIM } & V1 & $\mathrm{W} 1$ & $\overline{\mathrm{W} 2}$ & $\overline{\mathrm{W} 3}$ & $\mathrm{~W} 3$ & $\overline{\mathrm{W} 4}$ & W5 & $\mathrm{W} 6$ \\
\hline & $\sqrt{\mathrm{V} 2}$ & W2 & W3 & W3 & $\mathrm{W} 4$ & W5 & W6 & $\mathrm{W} 6$ \\
\hline & V3 & W3 & $\mathrm{W} 3$ & W4 & W5 & $\mathrm{W} 6$ & W7 & W7 \\
\hline & $\mathrm{V4}$ & W4 & $\mathrm{W} 4$ & W5 & W6 & $\mathrm{W} 6$ & W7 & W7 \\
\hline & v5 & W5 & W5 & W6 & W7 & W7 & W7 & W7 \\
\hline & V6 & W6 & W7 & W7 & W7 & W7 & W7 & W7 \\
\hline & V7 & W7 & W7 & W7 & W7 & W7 & W7 & W7 \\
\hline
\end{tabular}

Tablo 3. Rüzgar türbin verileri $38-44 \mathrm{~Hz}$ (Collected data from wind turbine $38-44 \mathrm{~Hz}$ )

\begin{tabular}{|c|c|c|c|c|c|c|c|c|}
\hline \multicolumn{2}{|c|}{$\begin{array}{l}\text { Sürücü } \\
\text { Frekansı } \\
(\text { Hz) }\end{array}$} & \multirow{2}{*}{$\begin{array}{l}44 \\
V_{C} \\
(V)\end{array}$} & \multirow{2}{*}{$\begin{array}{l}43 \\
V_{C} \\
(V)\end{array}$} & \multirow{2}{*}{$\begin{array}{l}42 \\
V_{C} \\
(V)\end{array}$} & \multirow{2}{*}{$\begin{array}{l}41 \\
V_{C} \\
(V)\end{array}$} & \multirow{2}{*}{$\begin{array}{l}40 \\
V_{C} \\
(V)\end{array}$} & \multirow{2}{*}{$\begin{array}{l}39 \\
V_{C} \\
(V)\end{array}$} & \multirow{2}{*}{$\begin{array}{l}38 \\
V_{C} \\
(V)\end{array}$} \\
\hline $\begin{array}{l}\mathbf{P}_{\mathbf{m}} \\
(\mathbf{W})\end{array}$ & $\begin{array}{c}\mathbf{I}_{\mathbf{C}} \\
\text { (A) }\end{array}$ & & & & & & & \\
\hline 1000 & 22,6 & 40,3 & 37,5 & 34,6 & & & & \\
\hline 900 & 20,4 & 41,5 & 38,8 & 36,2 & 32,4 & & & \\
\hline 800 & 18 & 43,3 & 40,8 & 38,5 & 35,2 & 32 & & \\
\hline 700 & 15,8 & 44,9 & 42,7 & 40,4 & 37,8 & 35 & 30 & \\
\hline 600 & 13,6 & 46,3 & 44,2 & 42 & 39,5 & 37 & 34,8 & 32,5 \\
\hline 500 & 11,3 & 47,3 & 45,4 & 43,4 & 41,2 & 38,8 & 36,7 & 34,7 \\
\hline 400 & 9,2 & 48,4 & 46,5 & 44,7 & 42,5 & 40,3 & 38,4 & 36,4 \\
\hline 300 & 7 & 49,7 & 47,8 & 45,8 & 43,8 & 41,7 & 40 & 38 \\
\hline 200 & 4,8 & 50,8 & 48,9 & 47 & 45 & 43 & 41,1 & 39,3 \\
\hline 100 & 2,5 & 51,8 & 50 & 47,9 & 46 & 44 & 42,2 & 40,4 \\
\hline 0 & 0,4 & 53,2 & 51,4 & 49,4 & 47,5 & 46 & 43,7 & 41,6 \\
\hline
\end{tabular}

Tablo 4. Rüzgar türbin verileri $31-37 \mathrm{~Hz}$ (Collected data from wind turbine $31-37 \mathrm{~Hz}$ )

\begin{tabular}{|c|c|c|c|c|c|c|c|c|}
\hline $\begin{array}{c}\text { Sürücü } \\
\text { Frekansı } \\
(\mathbf{H z})\end{array}$ & $\mathbf{3 7}$ & $\mathbf{3 6}$ & $\mathbf{3 5}$ & $\mathbf{3 4}$ & $\mathbf{3 3}$ & $\mathbf{3 2}$ & $\mathbf{3 1}$ \\
\hline $\begin{array}{c}\mathbf{P}_{\mathbf{m}} \\
(\mathbf{W})\end{array}$ & $\begin{array}{c}\mathbf{I}_{\mathbf{C}} \\
(\mathbf{A})\end{array}$ & $\begin{array}{c}\mathbf{V}_{\mathbf{C}} \\
(\mathbf{V})\end{array}$ & $\begin{array}{c}\mathbf{V}_{\mathbf{C}} \\
(\mathbf{V})\end{array}$ & $\begin{array}{c}\mathbf{V}_{\mathbf{C}} \\
(\mathbf{V})\end{array}$ & $\begin{array}{c}\mathbf{V}_{\mathbf{C}} \\
(\mathbf{V})\end{array}$ & $\begin{array}{c}\mathbf{V}_{\mathbf{C}} \\
(\mathbf{V})\end{array}$ & $\begin{array}{c}\mathbf{V}_{\mathbf{C}} \\
(\mathbf{V})\end{array}$ & $\begin{array}{c}\mathbf{V}_{\mathbf{C}} \\
(\mathbf{V})\end{array}$ \\
\hline $\mathbf{1 0 0 0}$ & 22,6 & & & & & & & \\
\hline $\mathbf{9 0 0}$ & 20,4 & & & & & & & \\
\hline $\mathbf{8 0 0}$ & 18 & & & & & & & \\
\hline $\mathbf{7 0 0}$ & 15,8 & & & & & & & \\
\hline $\mathbf{6 0 0}$ & 13,6 & & & & & & & \\
\hline $\mathbf{5 0 0}$ & 11,3 & 31,5 & & & & & & \\
\hline $\mathbf{4 0 0}$ & 9,2 & 33,7 & 31,2 & & & & & \\
\hline $\mathbf{3 0 0}$ & 7 & 35,5 & 33,7 & 30,8 & & & & \\
\hline $\mathbf{2 0 0}$ & 4,8 & 37 & 35,2 & 33 & 30,6 & 27,2 & & \\
\hline $\mathbf{1 0 0}$ & 2,5 & 38,3 & 36,5 & 34,4 & 32,1 & 29,7 & 27 & \\
\hline $\mathbf{0}$ & 0,4 & 40 & 37,7 & 36,3 & 33,7 & 31,6 & 29,3 & 0 \\
\hline
\end{tabular}

Klasik kontrol sistemleri, eğri uydurma gibi yöntemler MGNİ noktasının tespiti için denenmiş fakat istenen sonuç alınamamıştır. Bunun nedenini şöyle açıklayabiliriz: dikkat edilirse tablolarda koyuya boyanmış 2 kare bulunmaktadır. Burada $\mathrm{P}_{\mathrm{m}}$ maksimum çıkış gücünü, $V_{C}$ kıyıcı giriş gerilimini ve $\mathrm{I}_{\mathrm{C}}$ ise kıyıcı çıkış akımını göstermektedir. Bu iki karede de $\mathrm{V}_{\mathrm{C}}=37 \mathrm{~V}$ 'dur. Fakat karşlık gelen akım ve güç değerleri birinde $13.6 \mathrm{~A} / 600 \mathrm{~W}$ diğerin de ise $4.8 \mathrm{~A} / 200 \mathrm{~W}$ 'dır. $\mathrm{Bu}$ arada birinde rüzgar hızı (yani sürücü frekans1) $40 \mathrm{~Hz}$ diğerinde ise $37 \mathrm{~Hz}$ 'dir. $\mathrm{V}_{\mathrm{C}}$ $=37 \mathrm{~V}$ olduğu yerde hangi veri doğrudur? 


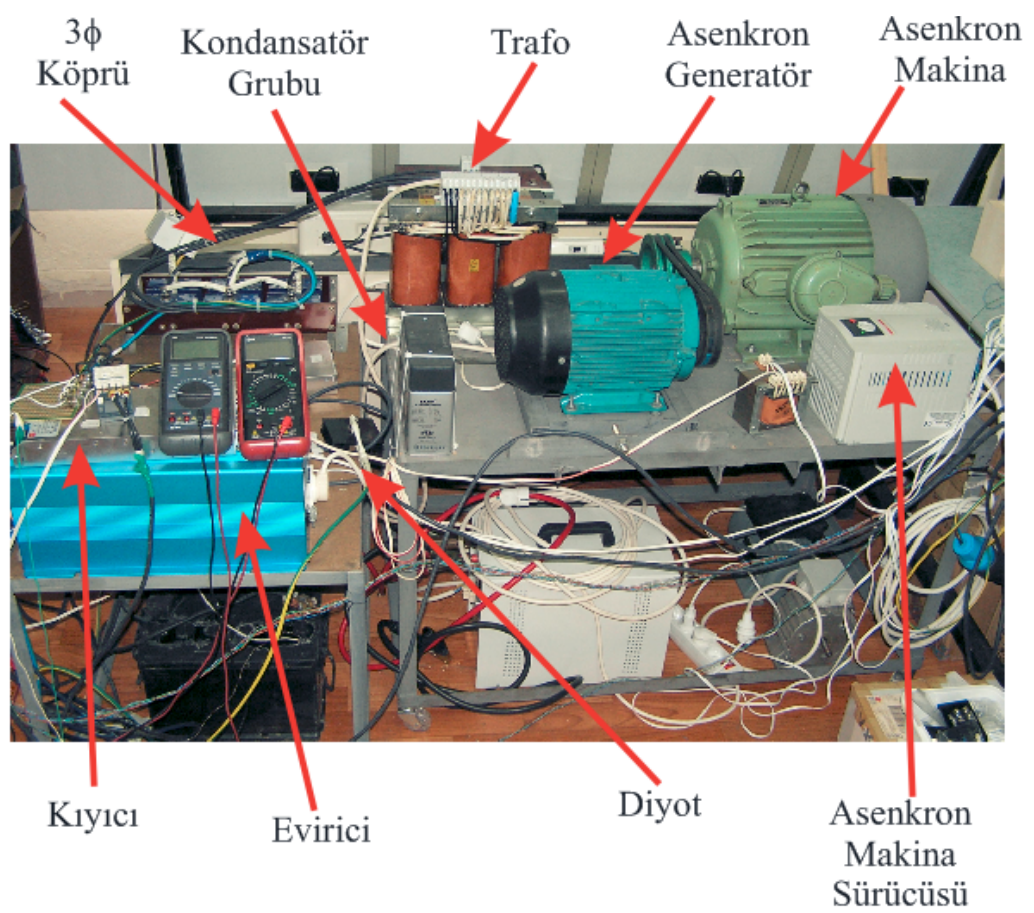

Şekil 6. Kurulan rüzgar türbin enerji üretim sistemi emülatörünün görünüşü (Wind turbine emulator energy production system)

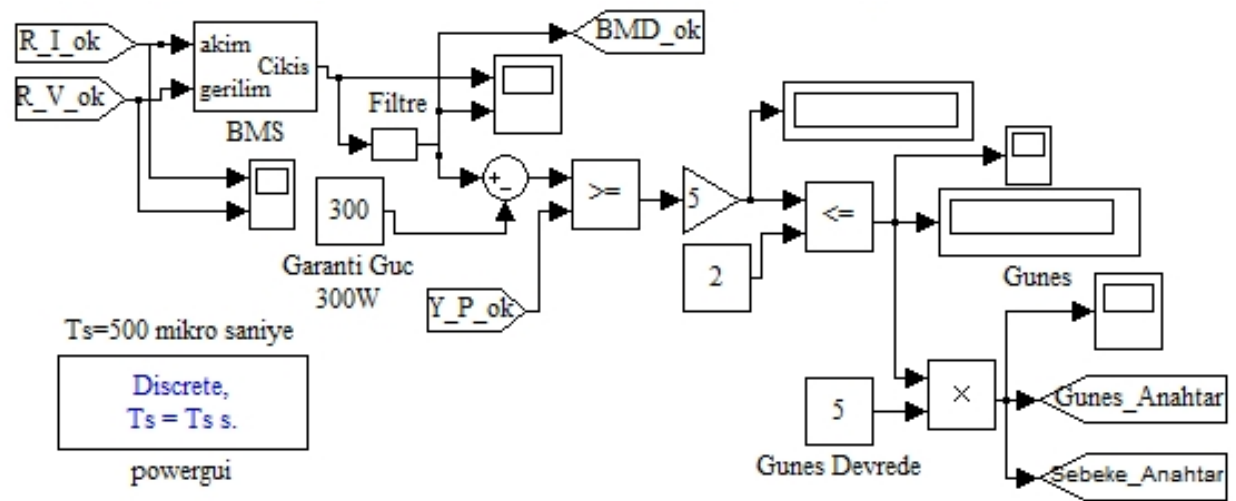

Şekil 7. Enerji yönetim MATLAB/Simulink programı (Energy management MATLAB/Simulink programme)

Bu noktada bilgisayarın kafası karışmakta ve program hata vermektedir ve bunun gibi pek çok nokta ve ara değer bulunmaktadır. Bu tablonun bilgisayara girilip istenen tepe güç değerlerinin hesaplanması amacı ile look up tabloları oluşturulmuş, eğriler uydurularak tepe güç değerini verecek uygun eğriyi kullanılarak bu noktayı hesaplamak için düzenlemeler yapılmış, 3 boyutlu grafiklerden faydalanılmaya çalışılmış fakat hiçbir sonuç alınamamıştır. $\mathrm{Bu}$ nedenle bulanık mantık sonuçlandırma yöntemi seçilmiştir.

Şekil 6'da deneysel olarak kurulan sistem görülmektedir.

BMS, tüm alt programları ile birlikte MATLAB/Simulink ortamında tasarlanmıştır. NI 6259 USB veri aktarım kartı kullanılarak sistemden alınan ölçümler bilgisayara aktarılmıştır.

\section{SONUÇLAR VE TARTIŞMA (RESULTS AND DISCUSSION)}

Enerji yönetim için tasarlanan MATLAB/Simulink programı Şekil 7'de görülmektedir.

Şekil 8 'de $\mathrm{t}=38-68 \mathrm{sn}$ ve $\mathrm{t}=86-88 \mathrm{sn}$ aralıklarında rüzgardan elde edilebilecek tepe güç değeri hesaplanmadığı için rüzgardaki değişimler nedeniyle üretilebilecek güç değeri tüketilen güç değerinin altında olduğu için sistemde çökmeler meydana gelmiştir. Bu esnada evirici devreden çıkmakta ve devreye girmeye çalışmaktadır. Bu esnada olması gereken; RES'in verebileceği tepe güç değerini belirlemek ve bu değerde yüklere güç aktarırken eksik kalan gücü akülerden, dizel jeneratörden veya şebekeden temin edebilecek akıllı bir sistemdir. Şekil 9'da Rüzgar Enerji Sistemi (RES)'e ait olan akım, gerilim ve güç değişimleri görülmektedir. 
Yuk Gerilimi

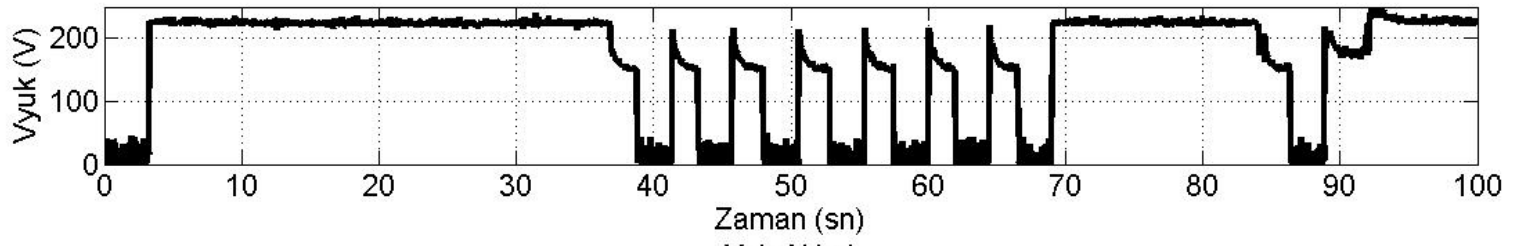

Yuk Akimi

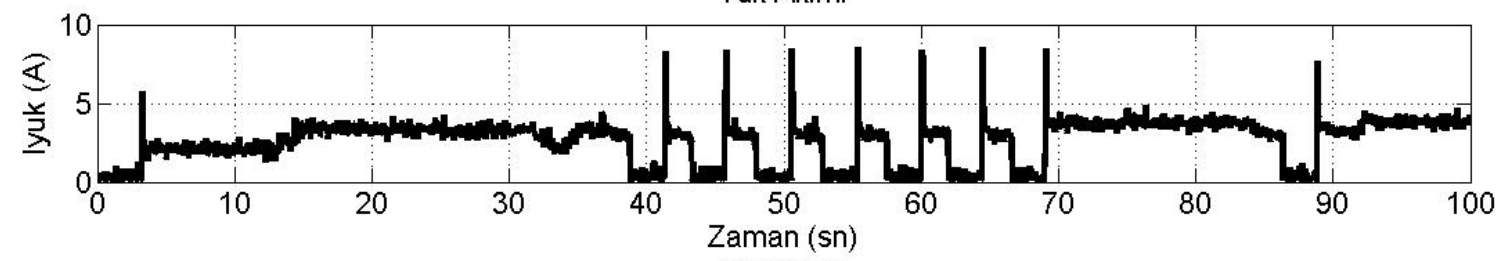

Yuk Gucu

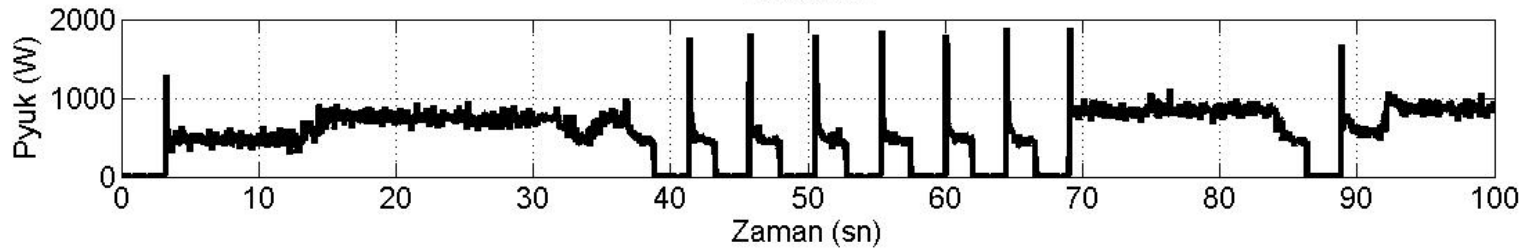

Şekil 8. Yük üzerindeki akım, gerilim ve güç değişimi (Voltage, current and power change of loads)

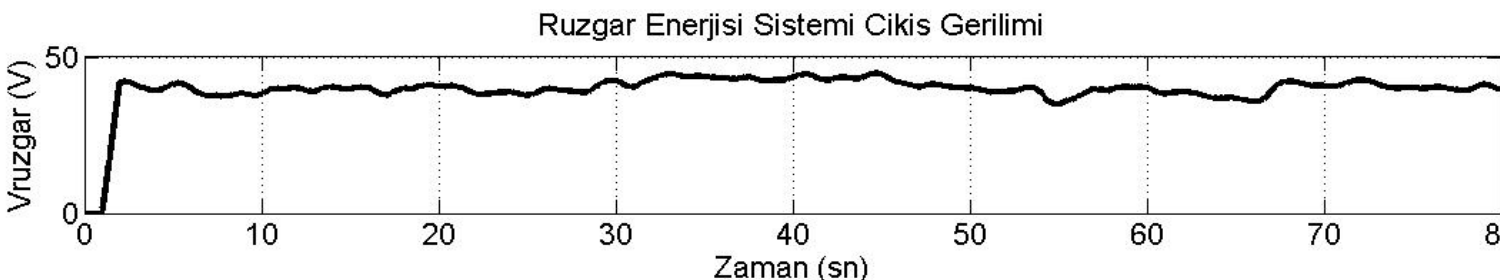

Ruzgar Enerjisi Sistemi Cikis Akimi

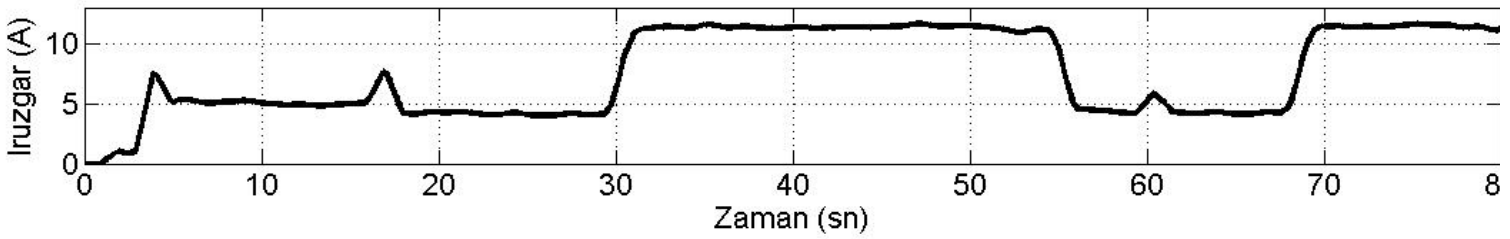

Ruzgar Enerjisi Gucu

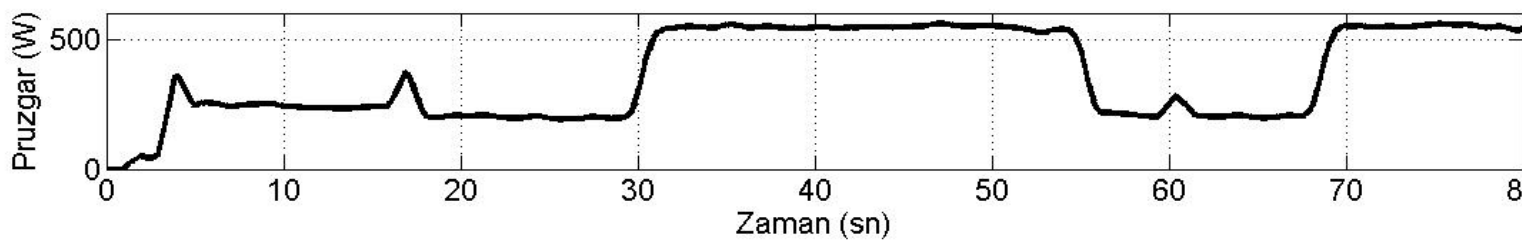

Şekil 9. Rüzgar enerji sisteminde akım, gerilim ve güç değişimi (Voltage, current and power variations of wind energy system)

Şekil 9'da yük miktarı farklı zaman aralıklarında değiştirildiği için RES'e ait grafiklerde, akım ve gerilim bilgilerinde değişmeler meydana gelmektedir. Fakat rüzgar hızı ve çekilen güçler nedeniyle sisteme aktardığı güç miktarı değişmektedir. Özellikle 3055.sn'ler arasında RES'den 550W'lı güç çekilmektedir.

Şekil 10'da yük üzerindeki akım, gerilim ve güç değişimleri görülmektedir. $\mathrm{t}=4-16 \mathrm{sn}$ aralığında $200 \mathrm{~W}$ ve $\mathrm{t}=16-100 \mathrm{sn} \quad$ aralığında $500 \mathrm{~W}^{\prime} l 1 \mathrm{k}$ yük bulunmaktadır.
Şekil 11'de t=0-16sn aralığında RES'de yaklaşık olarak 600W'lık tepe güç değeri bulunmaktadır. Bu aralıkta yük değeri $200 W^{\prime}$ 'dır. Daha sonra $t=16-100$ sn aralığında yük değeri 500W'a çıkmıştır. T=16-32sn aralığında RES 600W'lık tepe güç değerine sahiptir. $\mathrm{t}=32-55 \mathrm{sn}$ aralığında rüzgar hızı artmıştır. Bu esnada yük gücü hala 500 W'dır. RES bu aralıkta 1000 W'lık güç sağlayabilmektedir.

Benzer şekilde yapılan başka bir deneyde elde edilen sonuçlar Şekil 12 ile Şekil 14 arasında görülmektedir. Burada da BMS programı MGNI'yi çok güzel bir şekilde başarmaktadır [15]. 

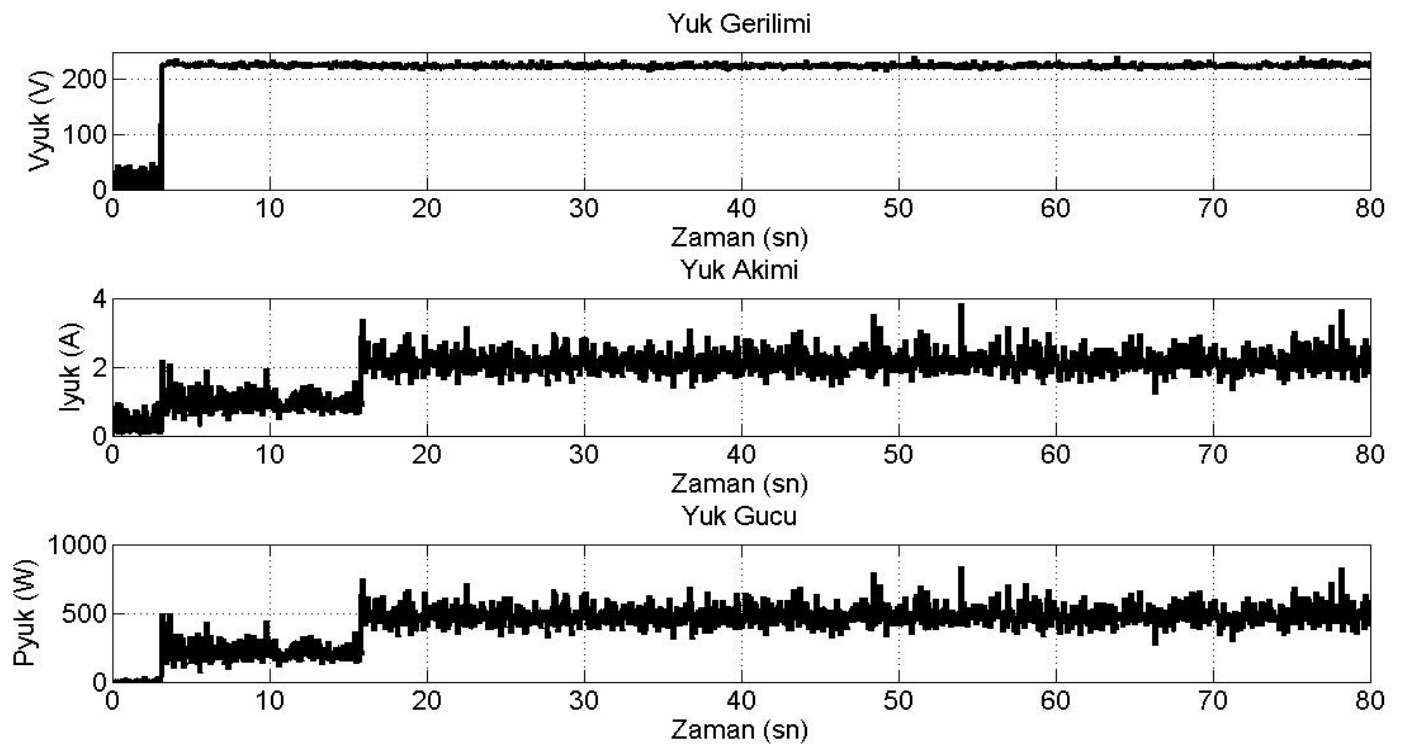

Şekil 10. Yük üzerindeki akım, gerilim ve güç değişimi deneysel sonuçlar (Voltage, current and power change of loads, experimental results)

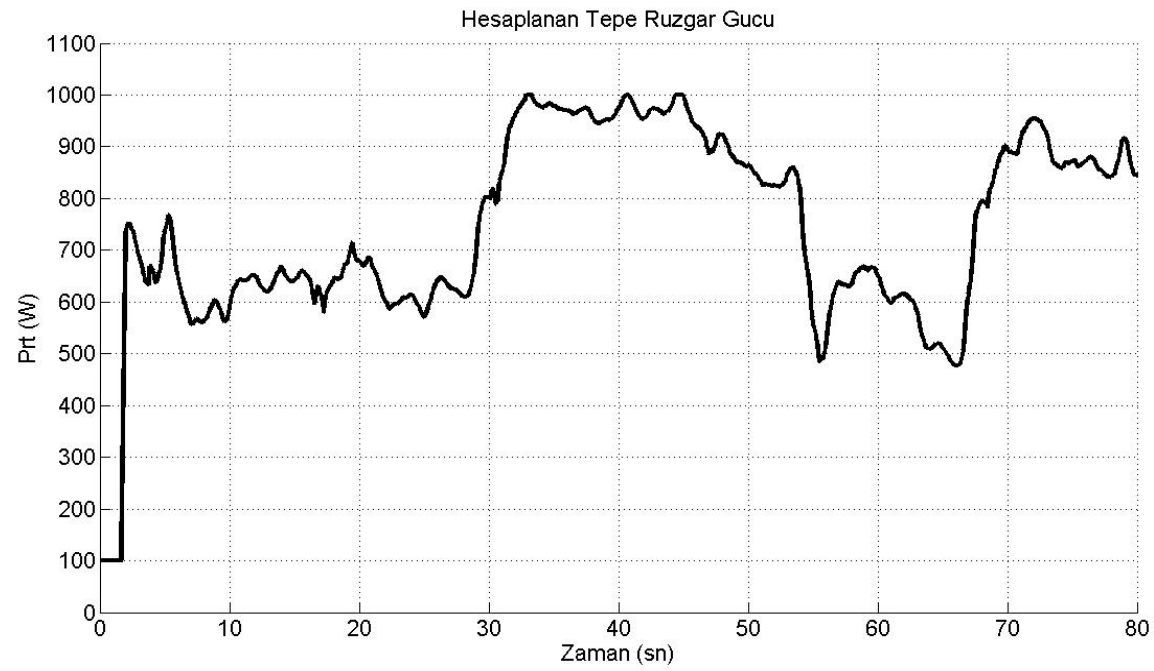

Şekil 11. BMS çıkışında RES'den elde edilebilecek tepe güç değerinin değişimi (Peak power changes obtained from WES using FDM algorithm)
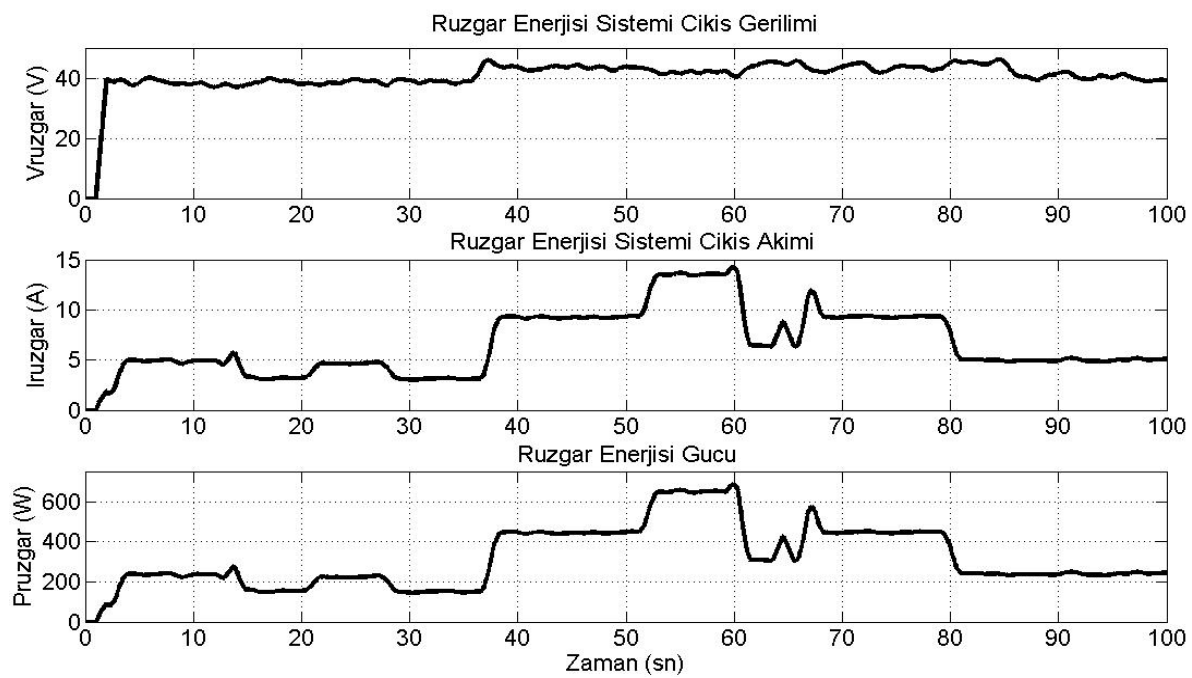

Şekil 12. Rüzgar enerji sisteminde akım, gerilim ve güç değişimi (Voltage, current and power variations of wind energy system) 

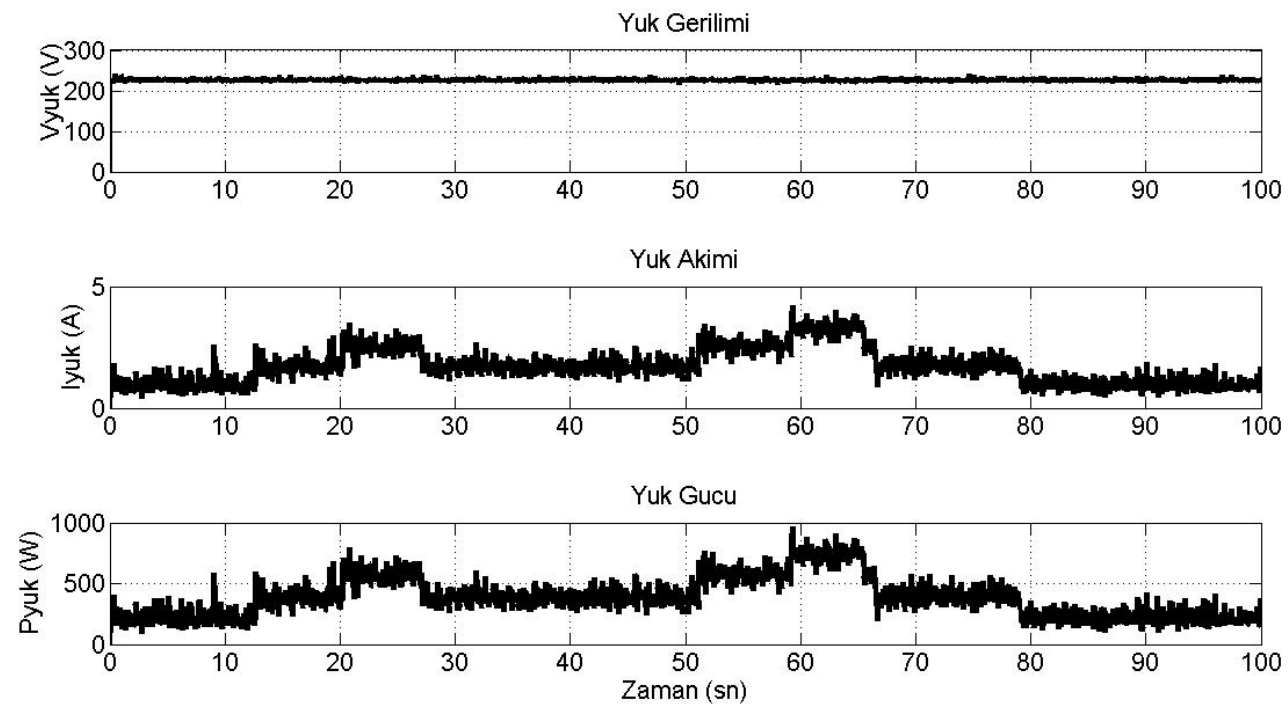

Şekil 13. Yük üzerindeki akım, gerilim ve güç değişimi (Voltage, current and power change of loads)

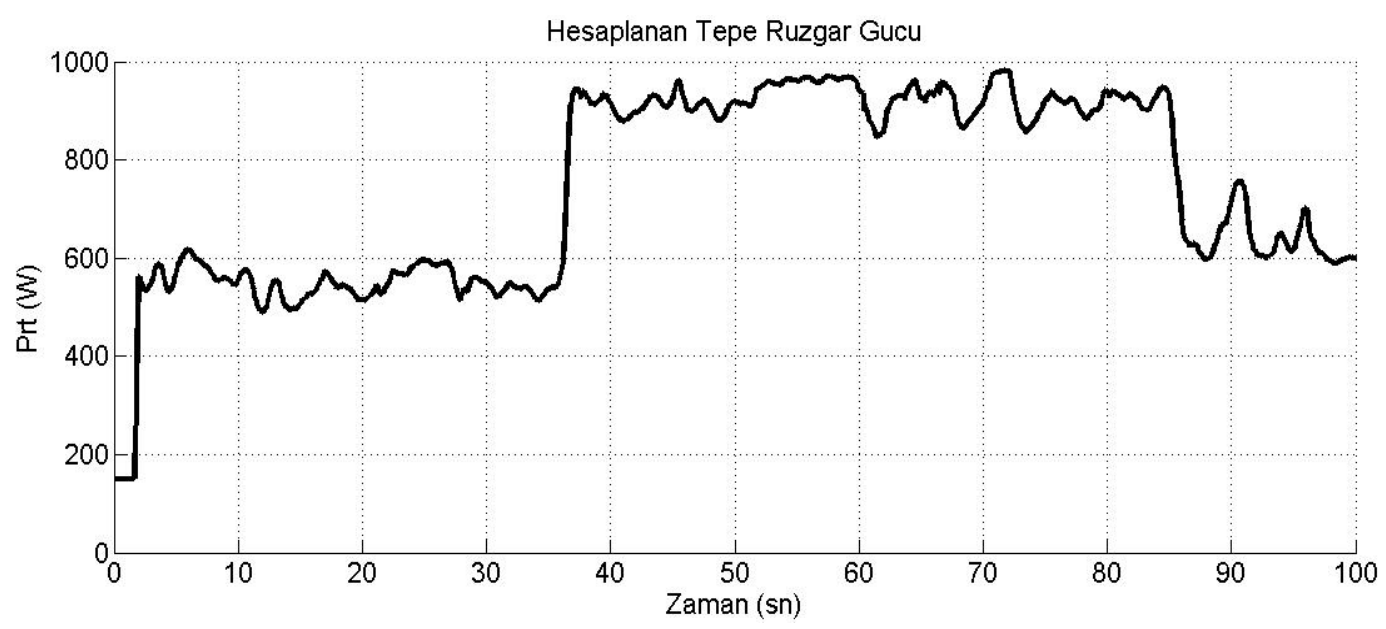

Şekil 14. RES tepe güç değişimi (Peak power changes obtained from WES)

\section{SONUCCLAR (CONCLUSION)}

Yapılan tüm denemelerde BMS etkin bir şekilde tepe güç değerini bulmaktadır. Sistemi zorlayarak yapılan deneylerde BMS sistemin nerede çökeceğini ve daha ne kadar yük kaldırabileceğini doğru bir şekilde hesaplamıştır. $\mathrm{Bu}$ verilerin 1şı̆̆ında tüm rüzgar türbinlerine buna benzer sistemler yerleştirerek ortamdan ölçüm almadan rüzgar hızındaki değişimlerde üretilebilecek tepe güç değerini bulabiliriz. Sistemde kullanılan akım ve gerilim algılayıcıları ortamla ilgili ölçüm yapan pahalı sistemlerden çok daha ucuz ve ekonomiktir. Tasarlanan program rüzgar türbinleri için alternatif bir maksimum güç noktası izleyici olarak kullanılabilir.

\section{TEŞEKKÜR (ACKNOWLEDGE)}

Bu proje Karadeniz Teknik Üniversitesi Bilimsel Araştırma Projeleri birimi tarafından desteklenmiştir. Proje No:2008.112.004.2.

\section{KAYNAKLAR (REFERENCES)}

1. Keyhani, A., Yenilenebilir Enerji Sistemlerinde Akıllı Şebeke Tasarımı, TMMOB Elektrik Mühendisleri Odası Yayınları, Ankara, Türkiye 2013.

2. Ackermann, T., Wind Power in Power Systems, John Wily \& Sons, Chisester, England, 2005.

3. Ata, R. ve Çetin, N. S., " $3 \mathrm{~kW}$ Otonom Bir Rüzgar Türbini Kurulumu ve Enerji Eldesi”, Journal of The Faculty of Engineering and Architecture of Gazi University, Cilt 23, No 1, 41-47, 2008.

4. Sharma, R. N. ve Madawala, U. K., "The Concept of a Smart Wind Turbine System", Renewable Energy, Cilt 39, No 1, 403-140, March 2012.

5. Zobaa, A. F. ve Bansal, R., Handbook of Renewable Energy Technology, World Scientific, Singapur, 2011.

6. Han, K. ve Chen, G., "A Novel Control Strategy of Wind Turbine MPPT Implementation for 
Direct-Drive PMSG Wind Generation Imitation Platform", Power Electronics and Motion Control Conference, Wuhan, 2255-2259, 17-20 Mayıs 2009.

7. İskender, İ. ve Genç, N., "Rüzgar Türbini ile Sürülen Çift Çıkışlı Asenkron Jeneratörün İncelenmesi ve Bulanık Mantık Kontrol Yöntemiyle Maksimum Çıkış Gücünün Elde Edilmesi", Journal of The Faculty of Engineering and Architecture of Gazi University, Cilt 24, No 2, 343-350, 2009.

8. Kesraoui, M., Korichi, N. ve Belkadi, A., "MPPT of Wind Energy Conversion System", Renewable Energy, Cilt 36, No 10, 2655-2662, Ekim 2011.

9. Ahmed, N. A., Othman, A. K. ve Alrashidi, M. R., "Development of an Efficient Utility Interactive Combined Wind/Photovoltaic/Fuel Cell Power System with an DC Bus Voltage Regulation", Electric Power System Research, Cilt 81, No 5, 1096-1106, Mayis 2011.

10. Camblong, H., Alegria, I. M., Roriguez, M. ve Abad, G., "Experimental Evaluation of Wind Turbines MPPT Controllers", Energy Conversion and Management, Cilt 47, No 1819, 2846-2858, 2006.

11. Mengi, O. O. ve Altas, I. H., "A Fuzzy Logic Control for Wind/Battery Renewable Energy
Production System", Turkish Journal of Electrical Engineering and Computer Sciences, TUBITAK, Cilt 20, No 2, 187-206, 2012, Turkey.

12. Altas, I. H. ve Mengi, O. O., "A Fuzzy Logic Voltage Controller for Wind Turbine / Supercapacitor Renewable Energy Source", International Conference on Electrical and Electronics Engineering (ELECO 2013), Bursa, 61-66, 28-30 Kasim 2013.

13. Lin, W. M. ve Hong, C. M., "Intelligent approach to Maximum Power Point Tracking Control Strategy for Variable-Speed Wind Turbine Generation System", Energy, Cilt 35, No 6, 2440-2447, 2010.

14. Lee, C. Y., Chen, P. H. ve Shen, Y. X., "Maximum Power Point Tracking (MPPT) System of Small Wind Power Generator Using RBFNN Approach", Expert Systems with Applications, Cilt 38, No 10, 12058-12065, Eylül 2011.

15. Mengi, O. Ö., Yenilenebilir Enerji Sistemlerinde Süreklilik için Akıllı Bir Enerji Yönetim Sistemi, Doktora Tezi, Karadeniz Teknik Üniversitesi, Fen Bilimleri Enstitüsü, Haziran 2011.

16. Zadeh, L. A., Fuzzy Sets, Information and Control, Cilt 8, 338-353, 1965. 